\title{
Displacement prediction of step-like landslide by applying a novel kernel
} extreme learning machine method

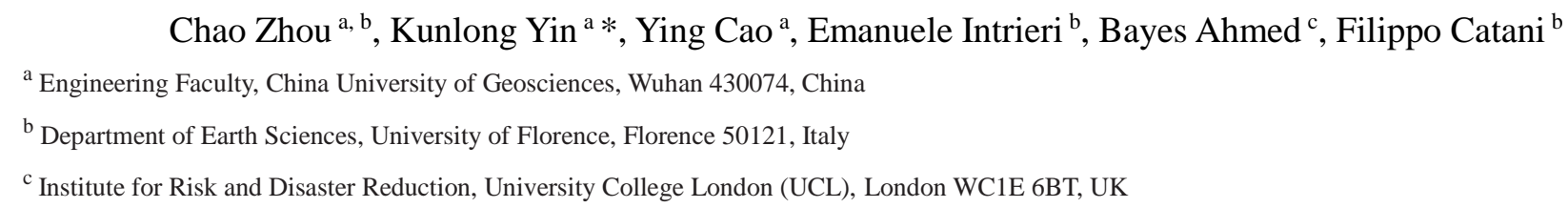

\section{Abstract}

Landslide displacement prediction is an essential component for developing landslide early warning systems. In the Three Gorges Reservoir area (TGRA), landslides experience step-like deformations (i.e. periods of stability interrupted by abrupt accelerations) generally from April to September due to the influence of precipitation and reservoir scheduled level variations. With respect to many traditional machine learning techniques, two issues exist relative to displacement prediction, namely the random fluctuation of prediction results and inaccurate prediction when step-like deformations take place. In this study, a novel and original prediction method was proposed by combining the Wavelet Transform (WT) and Particle Swarm Optimization-Kernel Extreme Learning Machine (PSO-KELM) methods, and considering the landslide causal factors. A typical landslide with a step-like behavior, the Baishuihe landslide in TGRA, was taken as a case study. The cumulated total displacement was decomposed into trend displacement, periodic displacement (controlled by internal geological conditions and external triggering factors respectively), and noise. The displacement items were predicted separately by multi-factor PSO-KELM considering various causal factors, and the total displacement was obtained by summing them up. An accurate prediction was achieved by the proposed method, including the step-like deformation period. The performance of the proposed method was compared with the multi-factor Extreme Learning Machine (ELM), Support Vector Regression (SVR), Backward Propagation Neural Network (BPNN), and single-factor PSO-KELM. Results show that the PSO-KELM outperforms other models, and the prediction accuracy can be improved by considering causal factors.

Keywords: Step-like landslides, Displacement prediction, Kernel Extreme Learning Machine, Three Gorges Reservoir 


\section{Introduction}

Landslides are a common natural hazard, which cause fatalities and economic damages worldwide (Petley 2012). In the Three Gorges Reservoir Area (TGRA) of China, thousands of landslides are threatening the surrounding environment. It is timely and significant to carry out accurate landslide displacement prediction, which is an essential component of develoing early warning systems for landslides (Casagli et al. 2010; Intrieri et al. 2013).

Since Saito proposed the empirical formula for landslide prediction (Saito 1965), numerous landslide prediction models have been developed (Fukuzono 1985; An et al. 2016; Carlà et al. 2016; Carlà et al. 2017; Conte et al. 2017; Zhou et al. 2017). They can be grouped into two categories: physical models and data-based models. The data-based models are more popular than physical models (Corominaset al. 2005) because of simple process and accurate prediction. Recently, a variety of Machine Learning (ML) models have been applied in landslide spatial and temporal prediction, such as Artifical Neural Network (ANN) (Du et al. 2013; Liu et al. 2016), Support Vector Machine (SVM) (Wu et al. 2016; Zhu et al. 2017), Decision Tree (Krkač et al. 2017; Ma et al. 2017), Extreme Learning Machine (ELM) (Cao et al. 2016; Vasu and Lee 2016; Huang et al. 2017), and so on.

Previous studies suggest that the ML models have achieved good performances in landslide displacement prediction. However, two deficiencies may limit its application: i.e. the fluctuation of prediction results and the inaccurate prediction in strong deformation period. For example, ELM randomly generates the connection weight between the input and hidden layers, which leads to the varied outputs, even if the inputs are totally the same (Huang et al. 2004; Yang et al. 2017). To address these limitations and improve the stability and accuracy of prediction, the Kernel Extreme Learning Machine (KELM) model, proposed by Huang et al in 2012, is applied to predict landslide displacement in this study. Simultaneously, the Particle Swarm Optimization (PSO) algorithm was utilized to optimize the parameters of KELM. The combination of these two methods are expected to increase the prediction accuray.

Landslide displacement is controlled by many factors and can be considered being constituted by several components. For example, the long-term deformation trend is controlled by the internal geological conditions, while the short-term deformation fluctuation is caused by external triggering factors (Glade et al. 2005; Du et al. 
2013), such as seasonal weather variations. The key of prediction, especially in strong deformation periods, is to establish accurate response relationship between causal factors and landslide deformation. Consequently, displacement time series should be decomposed and predicted separately with consideration of different causal factors in modelling.

In this study, a hybrid ML model for landslide displacement prediction was proposed with the consideration of causal factors. The Baishuihe landslide in the TGRA was taken as a case study. It has a typical step-like kinematic behavior, which means that long stable periods are interrupted by periodic abrupt accelerations. Based on the analysis of landslide step-like deformation, its displacement was decomposed into trend component, periodic component and noise by wavelet transform (WT). The precipitation, reservoir level and previous displacements were adopted as the causal factors of periodic displacement, while the previous displacements were used as the causal factors of trend displacement. The PSO-KELM was applied to predict both the trend and periodic displacements with respective to causal factors, and the total forecast displacement was the summation of the predicted displacements. To verify the performance of the proposed model (multi-factor PSO-KELM), the single-factor PSO-KELM and multi-factor Extreme Learning Machine (ELM), Support Vector Regression (SVR), and Backward Propagation Neural Network (BPNN) models were executed and compared.

\section{Displacement analysis of step-like landslides}

According to the creep deformation theory (Saito 1969), landslides approaching failures experience three consecutive stages (Fig. 1a): an initial deceleration (primary creep), a steady deformation (secondary creep) and eventually a hyperbolic acceleration which can lead to collapse. However, because of the influence of external triggering factors, landslides often show different deformation patterns. In the TGRA, under the influence of periodic precipitation and reservoir water level oscillations (Fig. 2), most landslides deform sharply from April to September every year. Then, when the triggers cease, typically from October to April, they become steady again (Miao et al. 2014). Consequently, the resulting cumulated displacement against time shows a step-like curve (Fig. 1b). 


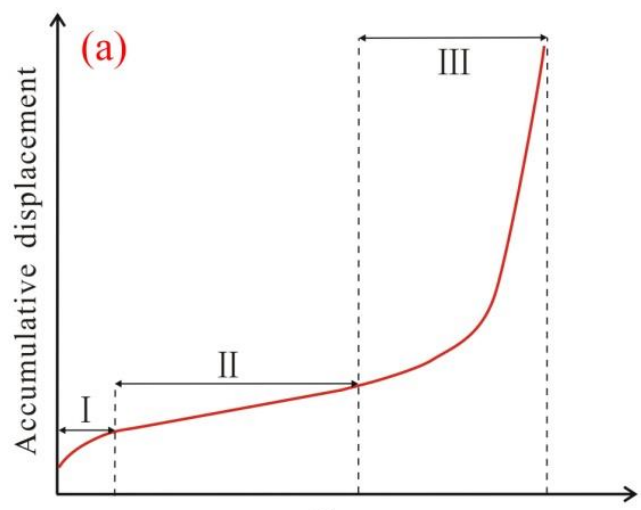

Time

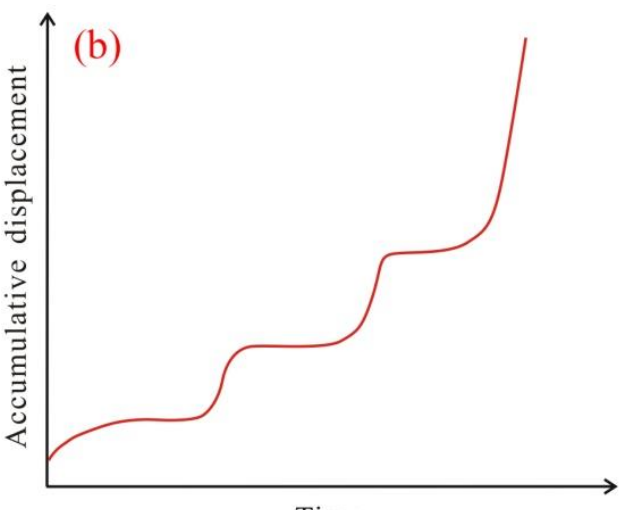

Time

Fig. 1: (a) Standard creep curve of landslide (I: decelerating creep stage; II: steady-state creep stage, and III: accelerating creep stage); and (b) Step-like landslide evolution curve

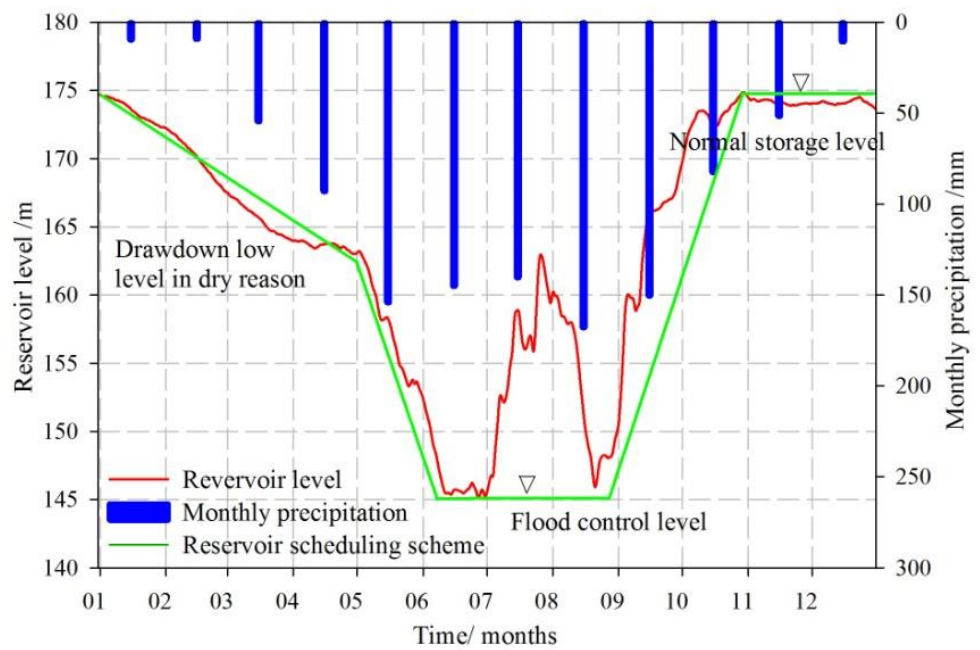

Fig. 2 Monthly precipitation and reservoir water level variation in the TGRA (2012)

The deformation evolution of step-like landslide is jointly affected by internal geological conditions and external triggering factors. The displacement controlled by internal geological conditions shows approximately monotonically increase in larger time scale (Fig. 1a), while the displacement induced by periodic rainfall and reservoir scheduling shows sudden increases in small time scale (Fig. 1b). These two components of the total displacement are defined as trend displacement and periodic displacement, respectively. At the same time, the system error always exists during deformation monitoring process. The cumulated displacement time series can be decomposed as follows:

$$
D=T+P+N
$$

Where $D$ is the original total cumulated displacement, $T$ is the trend displacement, $P$ is the periodic displacement and $N$ is the noise from system error of monitoring. 


\section{Displacement prediction model and methodology}

\subsection{Wavelet Transform}

Wavelet Transform (WT) is an effective analysis method for the signal process, which provides good localization in both time and frequency domains (Daubechies 1990). The WT can be divided into two classes, continuous wavelet transformation (CWT) and discrete wavelet transformation (DWT). Compared to the CWT, which requires complex computation and massive data, the DWT requires less time and is easy to be implemented, the definition is shown as follows:

$$
D W T_{y}(m, n)=2^{-\frac{m}{2}} \int_{-\infty}^{+\infty} s(t) \sigma^{*}\left(2^{-m} t-n\right) d t
$$

Where $m$ is the scaling constant and $n$ is the translating constant which is an integer; $s(t)$ is a signal time series and $\sigma^{*}(x)$ is the complex conjugate function.

The DWT algorithm proposed by Mallat (1989) has been widely used. It applies high-pass and low-pass filters to extract approximation and detail sequence from the original signal. The approximation sequence represents the low-frequency component, which contains trend information. The detail sequence represents the high-frequency component, which contains periodic information. In addition, a proper wavelet function is also important for WT. There are many wavelet functions, such as the Haar (1910), Meyer (1990), Daubechies (1992) and so on. In this study, Daubechies, which is smooth, orthogonal and compactly supported, was adopted to decompose landslide displacement time series.

\subsection{Kernel extreme learning machine}

Extreme learning machine (ELM) (Huang et al. 2006) is a novel ML model with feed-forward neural network training. Because of the excellent generalization ability and fast learning speed, ELM has been adopted in various fields recently (Lima et al. 2015; Barzegar et al. 2016; Yang et al. 2017). The main characteristic of ELM is that some parameters, such as the connection weight between the input and hidden layers, are generated randomly. The basic network structure of ELM is shown in Fig. 3. 


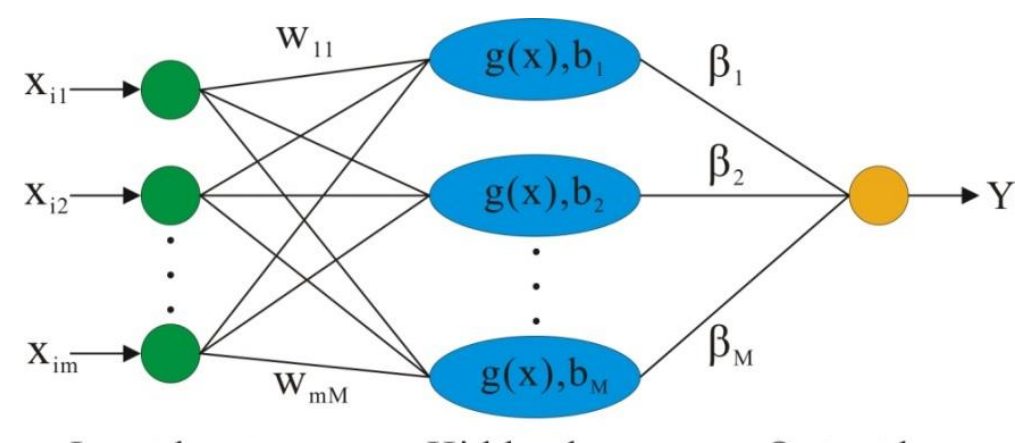

$$
f(x)=\sum_{i=1}^{N} \beta_{i} h\left(w_{i} \cdot x_{i}+b_{i}\right)
$$

Where $N$ is the number of hidden neurons; $\beta_{i}=\left[\beta_{1}, \beta_{2}, \cdots, \beta_{N}\right]$ is the output weight connecting the hidden nodes and the output nodes; $w_{i}=\left[w_{1 i}, w_{2 i}, \cdots, w_{N i}\right]$ is the weight vector connecting the hidden nodes and the input nodes; $b_{i}=\left[b_{1}, b_{2}, \cdots, b_{n}\right]$ is the threshold of the hidden nodes; $h(x)$ is a future mapping of hidden nodes. As the input weight $w$ and the hidden layer threshold $b$ are determined randomly, the goal of network training is to find the best output weight $\beta$, which can be calculated by the least square method:

$$
\beta^{\prime}=H^{+} Y
$$

Where $H^{+}$is the Moore-Penrose generalized inverse of the hidden layer output matrix $H$ (Huang et al. 2006).

In order to overcome the randomness of ELM, and improve its generalization capability and stability, Huang et al. (2012) extended ELM into kernel learning and proposed kernel-based ELM. Based on orthogonal projection method and ridge regression theory, the output weight $\beta$ can be calculated by adding a positive constant $1 / C$ as:

$$
\beta=H^{T}\left(1 / C+H H^{T}\right)^{-1} Y
$$

Hence, the output function of ELM is expressed as follows:

$$
f(x)=h(x) H^{T}\left(1 / C+H H^{T}\right)^{-1} T
$$

The kernel matrix for the ELM can be utilized to replace $h(x)$. Then, the output function of KELM can be 
written as follows:

$$
f(x)=\left[\begin{array}{c}
K\left(x, x_{1}\right) \\
\mathrm{M} \\
K\left(x, x_{N}\right)
\end{array}\right]^{T}\left(1 / C+H H^{T}\right)^{-1} T
$$

Where $K\left(x, x_{i}\right)$ is the kernel function. In this study, the radial basis function was applied as the kernel function.

\subsection{Particle Swarm Optimization}

The particle swarm optimization (PSO) algorithm was proposed by Eberhart and Kennedy (1995). It is a population-based stochastic optimization method and has been developed rapidly in recent years. Inspired by the feeding behavior characteristic of bird flock, PSO was applied to solve the optimization problem. In PSO algorithm, the particle is described by three basic features, namely position, speed and fitness value. Each particle represents a solution for the target problem. PSO achieves the search of optimal solution through the pursuit of optimal fitness value, which is obtained by calculating the objective function of target problem. In addition, the motion direction and the distance of the particles are determined by the speed feature. The search process of PSO is implemented through a loop iteration. In the loop iteration, PSO seeks the global best solution by adjusting the trajectory of each individual toward its own best location and the best particle of the entire swarm (Eberhart and Kennedy 1995). Considering that the performance of KELM will be affected by its parameters, PSO was adopted to seek appropriate parameters.

\subsection{The proposed model and performance evaluation}

As analyzed in Section 2, the step-like displacement of the studied landslide is composed of trend displacement, periodic displacement and noise. The displacement components are affected by different factors. In this proposed model, the noise was removed from the original total displacement at first; then, the total displacement (after denoising) was decomposed into two displacement components (see Section 4.3 for details). Considering the different mechanisms of trend and periodic displacements, they were separately modeled using the PSO-KELM, and the total displacement was obtained by adding them together. The flowchart of the proposed method is shown in Fig. 4. 


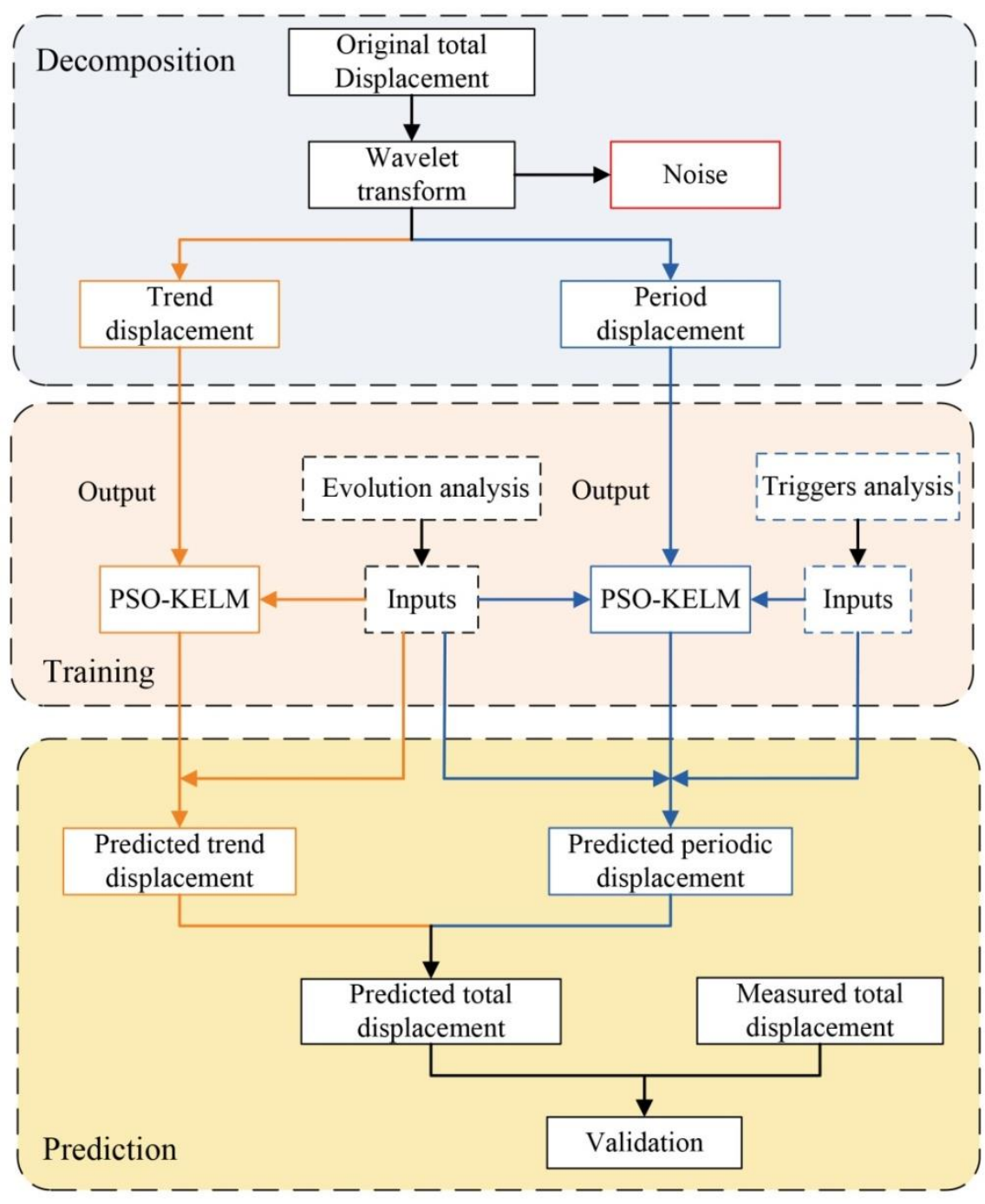

Fig. 4 The proposed prediction method for the step-like landslide displacements

In order to assess the model performance, four statistical indices were used, namely the root mean square error (RMSE), absolute percentage error (APE), mean absolute percentage error (MAPE) and relation coefficient (R). Larger R and smaller RMSE, APE and MAPE indicate higher prediction performance. The formulas of the four indices are shown as follows:

$R M S E=\sqrt{\frac{1}{N} \sum_{i=1}^{N}\left(\hat{D}_{i}-D_{i}\right)^{2}}$

$$
A P E=\left|\frac{\hat{D}_{i}-D_{i}}{D_{i}}\right|
$$

$$
M A P E=\frac{1}{N} \sum_{i=1}^{N}\left|\frac{\hat{D}_{i}-D_{i}}{D_{i}}\right|
$$




$$
R=\frac{\sum_{i=1}^{N}\left(D_{i}-\bar{D}\right)\left(\hat{D}_{i}-\overline{\hat{D}}\right)}{\sqrt{\sum_{i=1}^{N}\left(D_{i}-\bar{D}\right)^{2}} \sqrt{\sum_{i=1}^{N}\left(\hat{D}_{i}-\overline{\hat{D}}\right)^{2}}}
$$

where $N$ is the number of cumulated displacement values; $D_{i}$ is the observed cumulated displacement

values; $\hat{D}_{i}$ is the predicted cumulated displacement values; $\bar{D}$ is the mean of observed values; $\overline{\hat{D}}$ is the mean of predicted values.

\section{Case study: the Baishuihe landslide}

\subsection{Geological conditions}

Baishuihe is located in the county of Zigui, Hubei province $\left(31^{\circ} 01^{\prime} 34^{\prime \prime} \mathrm{N}, 110^{\circ} 32^{\prime} 09^{\prime \prime} \mathrm{E}\right), 56$ kilometers away from the Three Gorges Dam (Fig. 5). The landslide is fan-shaped in plane with a main sliding direction of $20^{\circ}$ NE. The area of Baishuihe is about $0.42 \mathrm{~km}^{2}$, with the maximum length and width of $780 \mathrm{~m}$ and $700 \mathrm{~m}$, respectively (Fig. 6). The average depth of sliding mass is approximately $30 \mathrm{~m}$ with an estimated volume of $12,600 \mathrm{~m}^{3}$. The landslide elevation extends from $75 \mathrm{~m}$ to $390 \mathrm{~m}$, and the slope is gentle in the middle part and steep in both the front and rear part (Fig. 7).

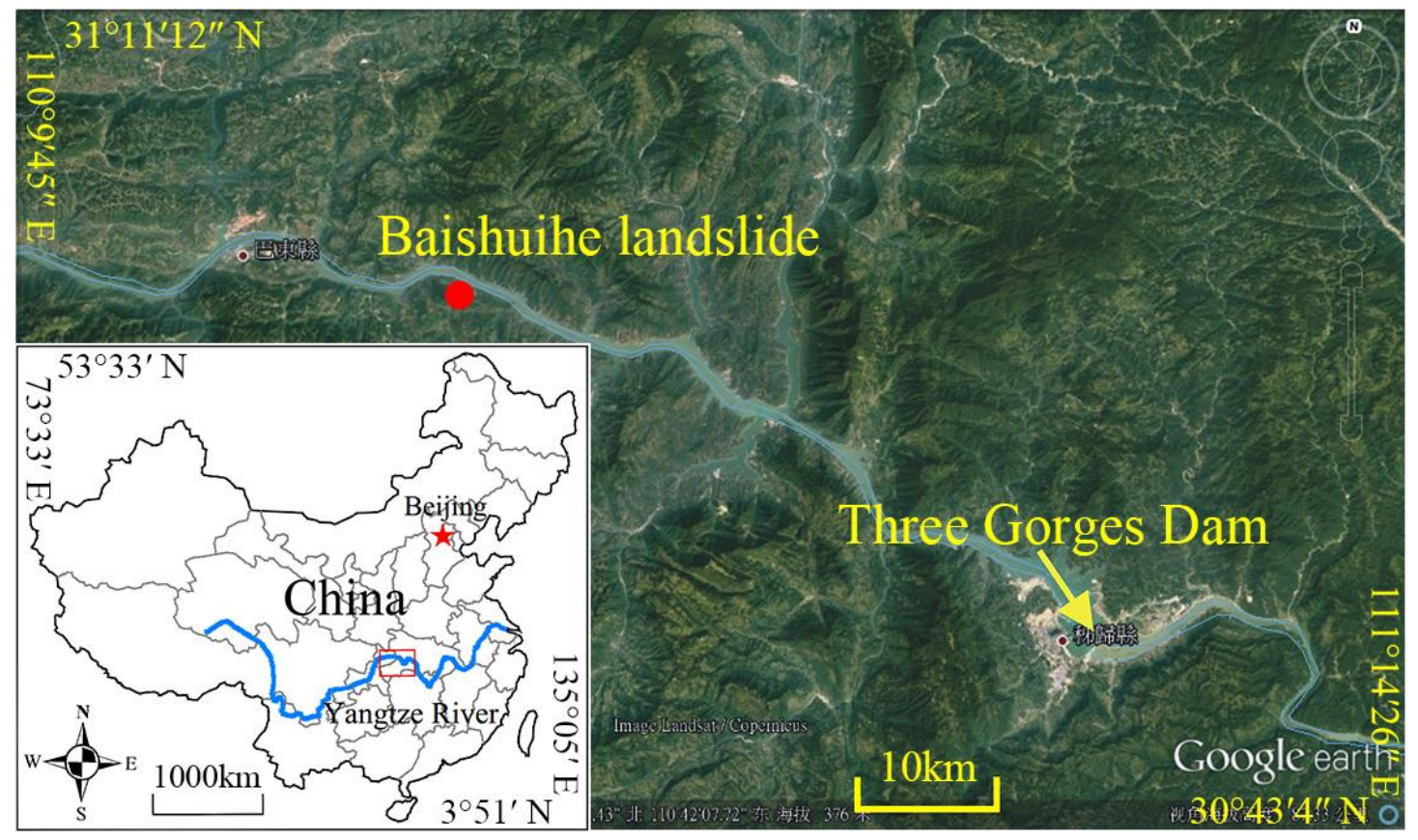

Fig. 5 The location of Baishuihe landslide (Satellite image from Google Earth) 


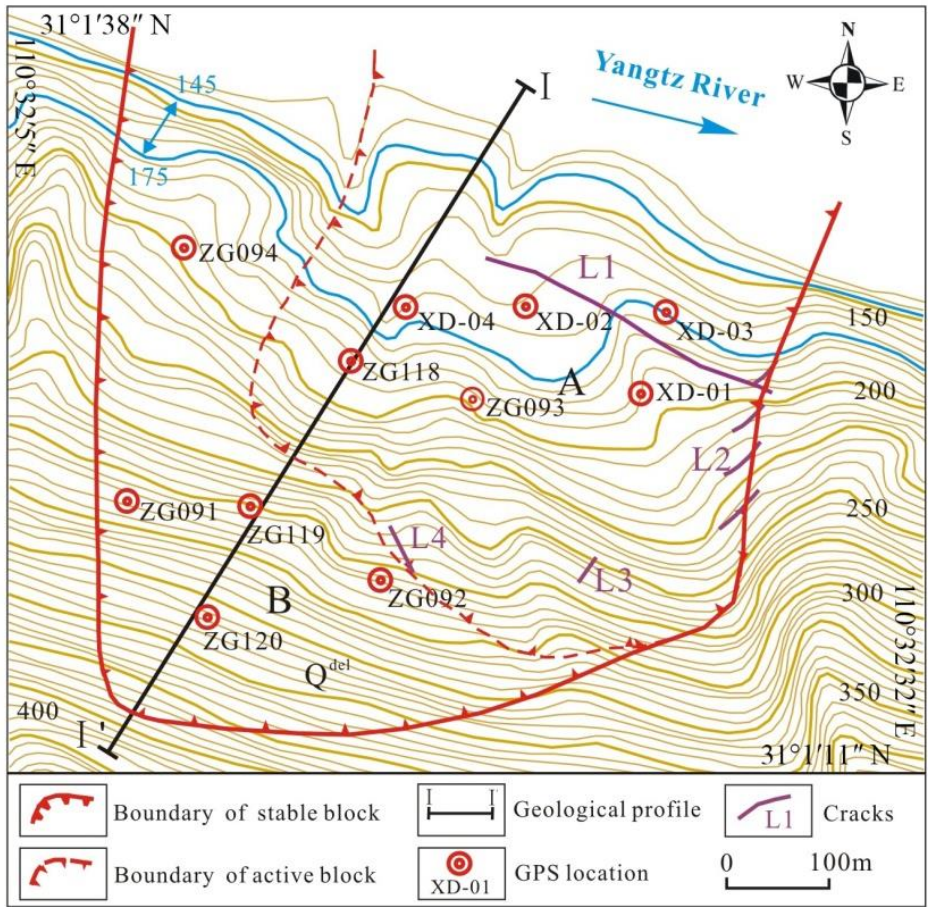

Fig. 6 Topographical map of the Baishuihe landslide (modified from Li et al. 2010)

The main materials of Baishuihe landslide are quaternary deposits, which contain silty clay and fragmented rubble with a loose and chaotic structure. The bedrock underlying the landslide is composed of silty mudstone sand muddy siltstones of the Jurassic Xiangxi Formation (Chen et al. 2010; Miao et al. 2014; Yabe and Hayasaka 1920), with the dip direction ranging from $15^{\circ}$ to $20^{\circ}$ and the dip angle from $32^{\circ}$ to $36^{\circ}$ (Fig. 7 ).

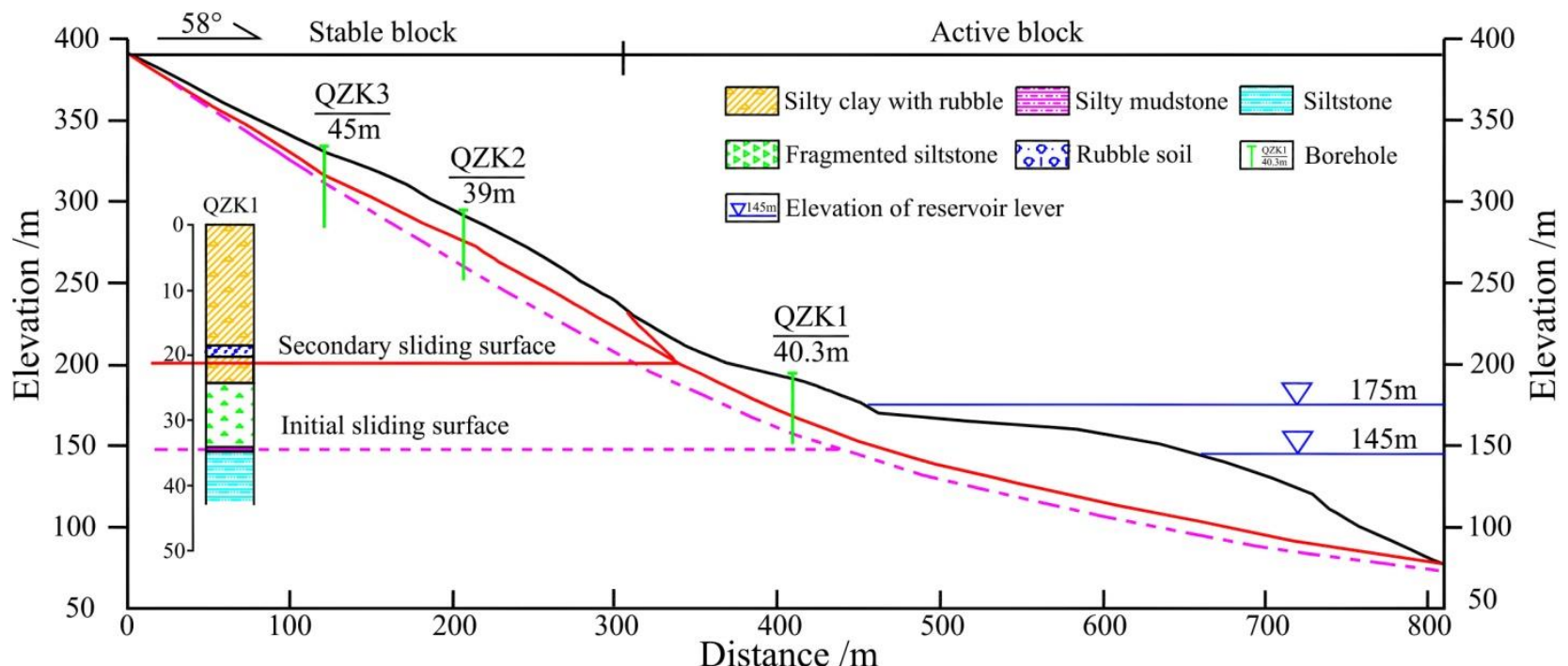

Fig. 7 Geological profile I-I' of the Baishuihe landslide (modified from Li et al. 2010)

\subsection{Deformation characteristic analysis}

The depth of the sliding zone was identified through boreholes and inclinometers. As shown in Fig.7, there are two sliding surfaces, namely initial sliding surface and secondary sliding surface, occurring at different depths. The 
depth of the secondary sliding surface varies from $12 \mathrm{~m}$ to $21.5 \mathrm{~m}$, while the initial sliding surface is deeper than 30m. A possible explanation for the formation of the secondary sliding surface is that a complete failure along the initial sliding surface would have required much more energy due to the large volume and complex geological conditions of the Baishuihe landslide.

According to field investigation and monitoring data analyses, the Baishuihe landslide can be divided into two blocks, the active block and the relatively stable block. The cumulated displacement of the active block is found as much as 3,500mm from the year 2003 to 2014 (Fig. 8). The stable block is deforming very slowly and the cumulated displacement is approximately 20mm. Apparently, the deformation velocity varies spatially. The deformation of the eastern part is stronger than the western part, while the front part experiences larger deformation than the rear part.
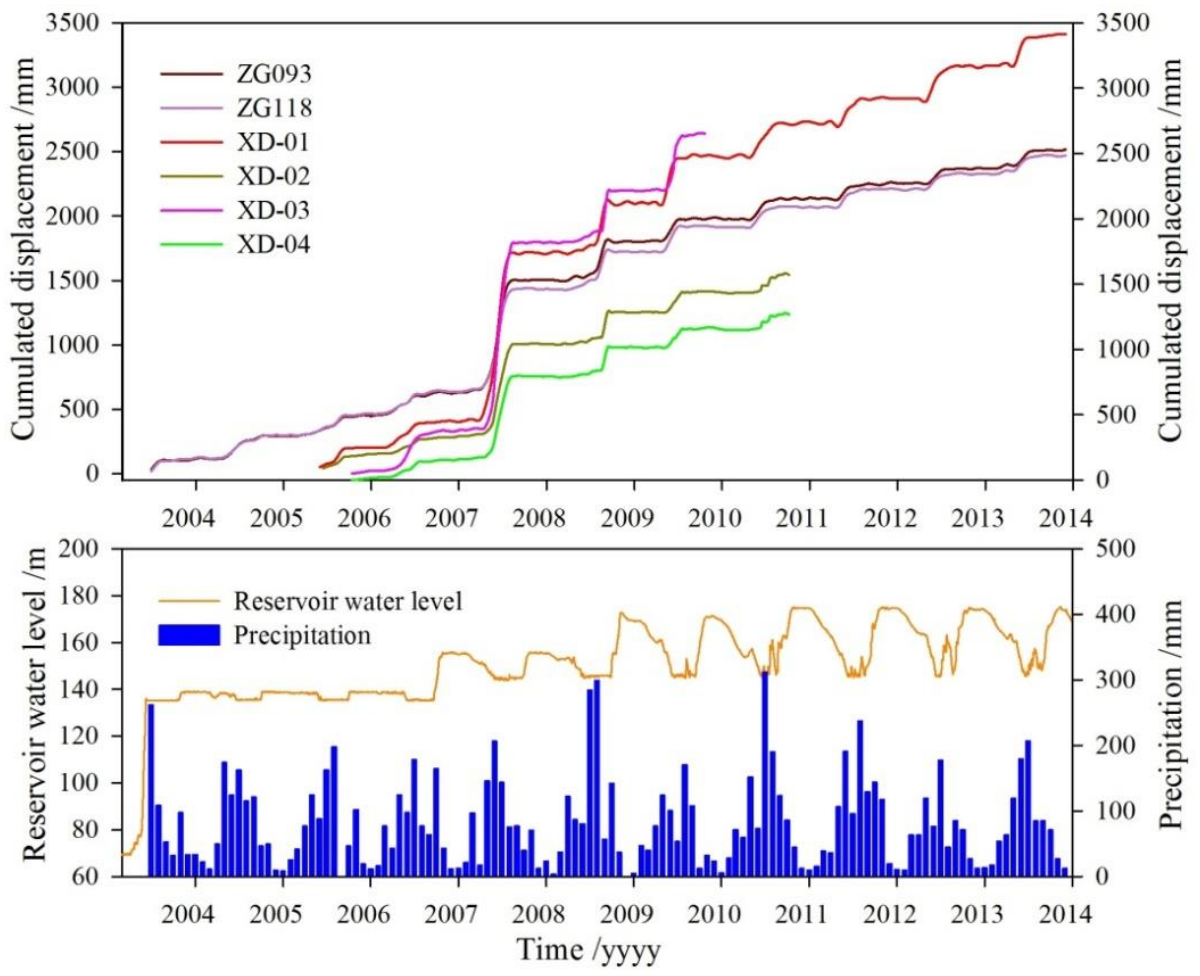

Fig. 8 The monitoring data of the Baishuihe landslide

Since the first impoundment of the Three Gorges Reservoir in June 2003, there were many deformation indications found on Baishuihe landslide. In the early stage of impoundment, the reservoir water level rose from $75 \mathrm{~m}$ to $145 \mathrm{~m}$, the Baishuihe landslide deformed gradually and several cracks developed in the front part of the landslide (Table 1, Fig. 6 and 8). In 2007, when the reservoir level firstly reached 156m and dropped from 156m to $145 \mathrm{~m}$ from February to August, combining the influence of the heavy precipitation of $518.2 \mathrm{~mm}$ in July, the 
landslide deformed greatly and the cumulated displacement reached 1711.4mm (Fig. 8).

Table 1 The main macroscopic deformation phenomena in the Baishuihe landslide

\begin{tabular}{|c|c|c|c|c|c|}
\hline \multicolumn{2}{|c|}{ Time } & \multirow{2}{*}{$\begin{array}{c}\text { Rainfall } \\
(\mathrm{mm})\end{array}$} & \multirow{2}{*}{$\begin{array}{c}\text { Reservoir } \\
\text { Water level(m) }\end{array}$} & \multirow{2}{*}{$\begin{array}{c}\text { Deformation } \\
\text { velocity }(\mathrm{mm} / \mathrm{d})\end{array}$} & \multirow{2}{*}{ Description of main deformation indications } \\
\hline Year & Month & & & & \\
\hline 2003 & $7 \sim 9$ & 228.8 & $135( \pm 0.2)$ & $1.8 \sim 2.1$ & $\begin{array}{l}\text { Generated the tensile crack } L 1 \text { with direction of } \\
320^{\circ} \text {, width of } 5 \sim 20 \mathrm{~mm} \text { and length of } 5 \sim 300 \mathrm{~m} \text { (Fig. } 9 \mathrm{a} \text { ); } \\
\text { generated the shear crack } L 2 \text { with direction of } \\
10^{\circ} \sim 40^{\circ} \text {, width of } 5 \sim 15 \mathrm{~mm} \text { and length of } 5 \sim 20 \mathrm{~m} \text { (Fig. } \\
9 \mathrm{~b} \text { ). }\end{array}$ \\
\hline 2005 & $8 \sim 10$ & 178.4 & $135.5( \pm 0.5)$ & $1.8 \sim 3.0$ & $\begin{array}{l}\text { Generated the shear crack } L 3 \text { with direction of } 50^{\circ} \text {, length } \\
\text { of } 50 \mathrm{~m} \text { and width of } 10 \sim 20 \mathrm{~mm} \text { (Fig. } 9 \mathrm{c} \text { ); generated the } \\
\text { tensile crack } L 4 \text { with direction of } 300^{\circ} \text {, length of } 50 \mathrm{~m} \text { and } \\
\text { width of } 10 \sim 20 \mathrm{~mm} \text { (Fig. } 9 \mathrm{~d} \text { ); }\end{array}$ \\
\hline 2007 & $5 \sim 8$ & 518.2 & $148.5 \sim 146$ & $0.3 \sim 50.9$ & $\begin{array}{l}\text { The landslide deformed the most in this year. All the } \\
\text { cracks developed greatly (Fig. 9); a series of cracks } \\
\text { developed in the rear and formed the landslide boundary. } \\
\text { Some small cracks developed in the west part of the } \\
\text { landslide. }\end{array}$ \\
\hline 2009 & $5 \sim 7$ & 120.2 & $155.9 \sim 145.5$ & $2.2 \sim 6.7$ & $\begin{array}{l}\text { The cracks kept developing, especially in the eastern and } \\
\text { front part of the landslide. }\end{array}$ \\
\hline
\end{tabular}
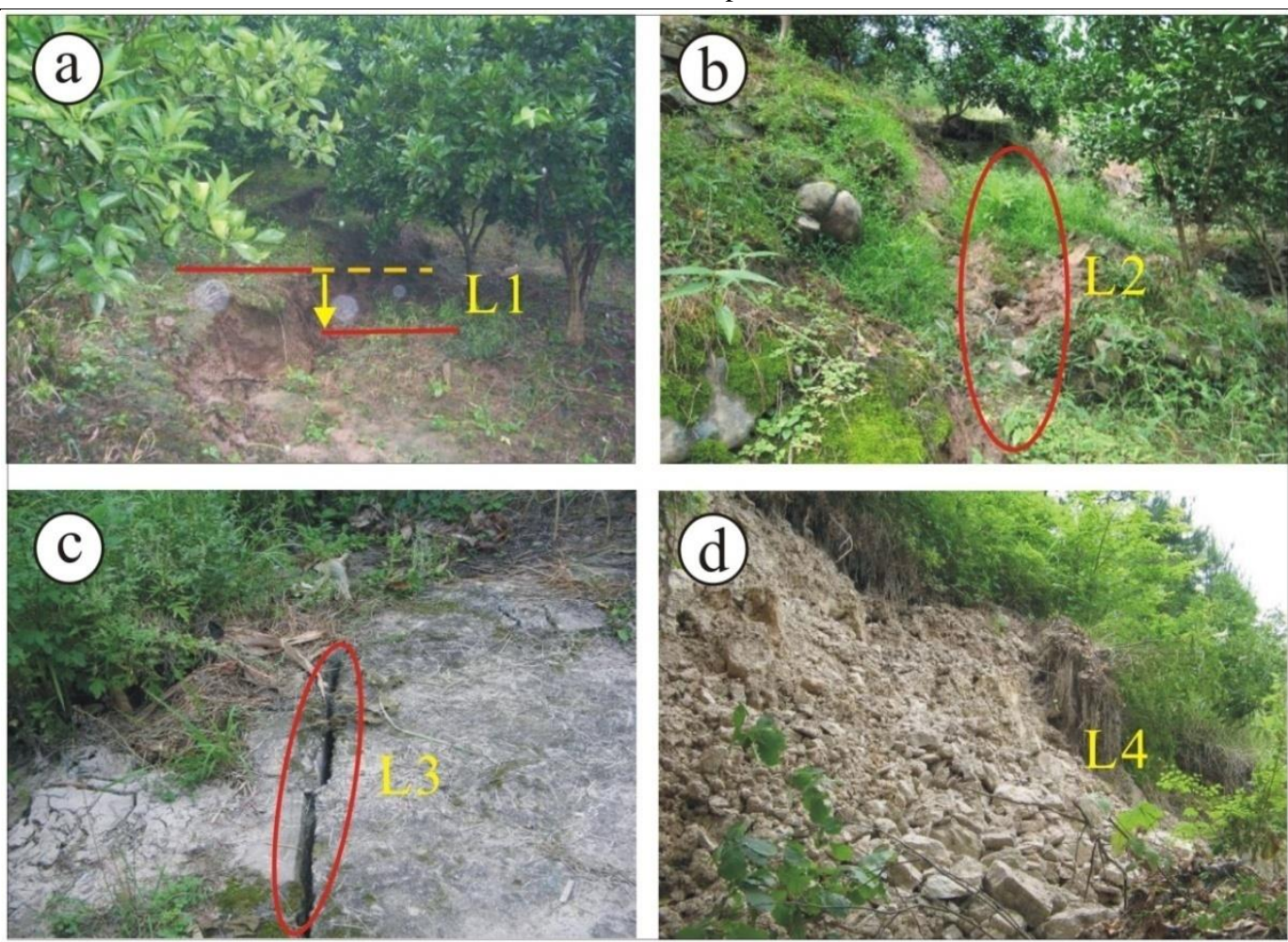

Fig. 9 Deformation indications on Baishuihe landslide

As a typical landslide with step-like deformation, the displacement of Baishuihe was increasing from April to

September each year under the joint influence of heavy precipitation and drawdown of the reservoir water level.

However, from October to April in the following year, while the reservoir level was stable $(175 \mathrm{~m})$ and the precipitation was gentle, the landslide was in a stable state, experiencing small displacement. 


\subsection{Decomposition of displacement time series}

The step-like deformation of landslide is a complex, dynamic and nonlinear system (Eid 2014). According to the deformation analysis in Section 4.2, Baishuihe landslide is a retrogressive landslide under combined influence of precipitation and reservoir level. The GPS monitoring station XD-01 in the front part was selected to establish the landslide forecasting model, since its monitoring data showed the highest cumulated displacement (Fig. 8). In the TGRA, the reservoir level has been regularly fluctuating between $145 \mathrm{~m}$ and $175 \mathrm{~m}$ since 2009 (Fig. 8). Hence, the monitoring data after 2009 was adopted for modelling.

Noise is unavoidable for the surface deformation monitoring by GPS and should be removed at first. Wavelet transform is an effective denoising method, and the automatic one-dimensional denoising method in the wavelet toolbox of MATLAB was used to remove the system noises from the original displacement sequence. In the frequency domain, the low-frequency component represents the trend displacement, while the high-frequency component represents the periodic displacement. The DWT with the function of Daubechies 4 was applied to divide the total cumulated displacement into the trend and periodic displacement (Fig. 10). The DWT process is performed in the wavelet toolbox of MATLAB as well.

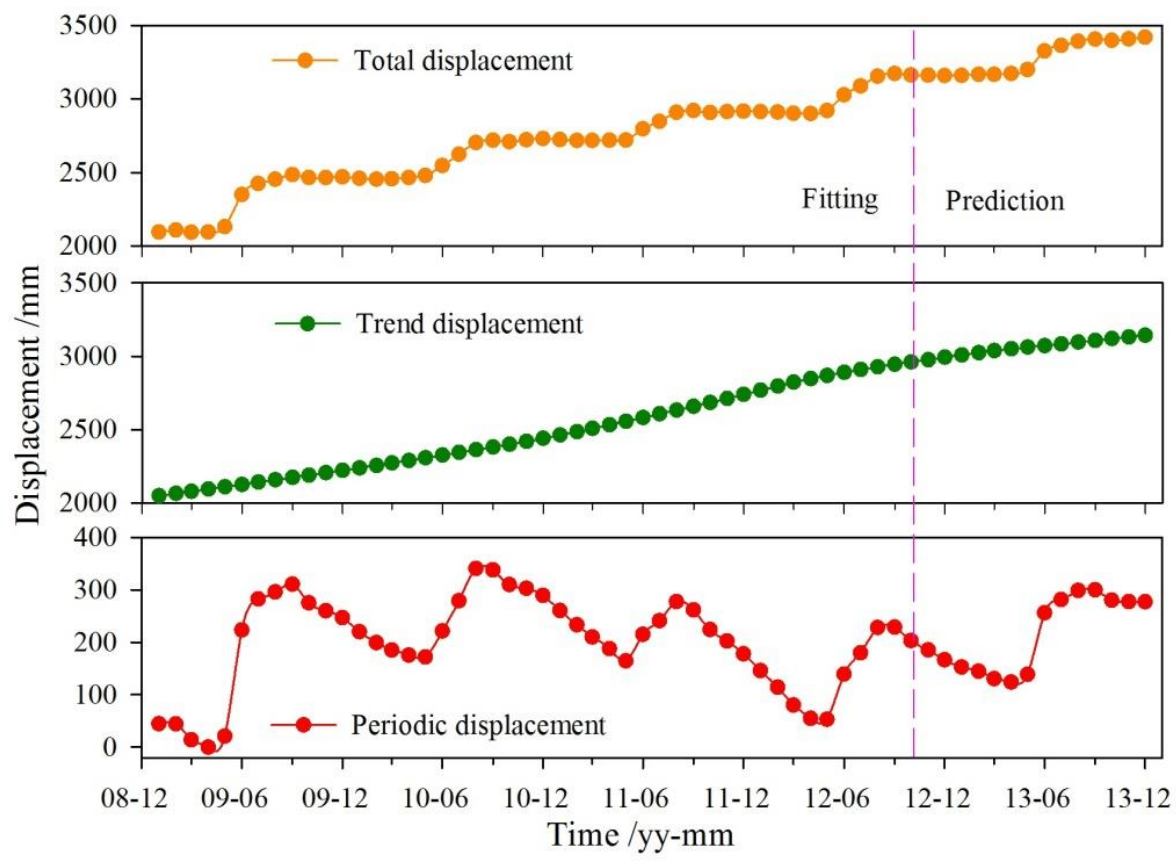

Fig. 10 Displacement decomposition result of XD-01

In addition, the ML models are more sensitive to the data ranging from 0 to 1 . Therefore, all the data should be normalized into the desired range using the following formula before modelling: 


$$
\bar{x}=\frac{x-x_{\min }}{x_{\max }-x_{\min }}
$$

Where, $\bar{x}$ are the normalized values, $x$ are the original values, $x_{\max }$ is the maximum value of a sequence, $x_{\min }$ is the minimum value of a sequence.

\subsection{Prediction of trend displacement}

The trend displacement is controlled by internal geological conditions. As shown in Fig. 10, the trend displacement of the landslide is a smooth and monotonically increasing sequence, which is similar to the secondary stage of the standard creep curve (Fig. 1a). Therefore, we can infer that Baishuihe landslide is in a steady deformation state in large time scale. The PSO-KELM was applied to predict the trend displacement of Baishuihe landslide. In the modelling of trend displacemetn, the monthly displacement from January 2009 to December 2012 was used to train, while the monthly displacement from January to December in 2013 was used for testing. The trend displacement over the past 1, 2, 3 months was used as inputs (Zhou and Yin 2014; Cao et al. 2016). Some samples of the data used in the modelling are shown in Table 2. The optimal parameters of KELM were searched with PSO, whose results were $C=133.5672$ and $\gamma=49.8025$, where $C$ is the regularization coefficient and $\gamma$ is the parameter of Kernel function. As shown in Fig. 11, the PSO-KELM achieved a good performance in trend displacement; the results of RMSE, MAPE and R were 2.397, 0.001 and 0.998 , respectively.

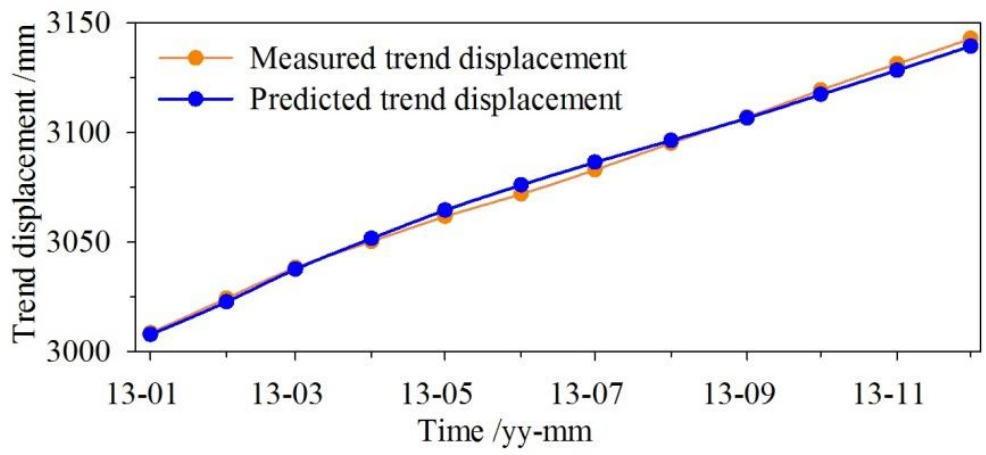

Fig. 11 The predicted and measured values of the trend displacement

Table 2 Some data samples used in the modelling of trend displacement

\begin{tabular}{llllll}
\hline Time & Input 1 & Input 2 & Input 3 & Output & Notes \\
\hline Jan 2013 & 0.8332 & 0.8477 & 0.8626 & 0.8770 & Inputs 1-3 are the trend displacement over \\
Feb 2013 & 0.8477 & 0.8626 & 0.8770 & 0.8914 & the past 1, 2 and 3 month respectively. \\
Mar 2013 & 0.8626 & 0.8770 & 0.8914 & 0.9042 & Output is the trend displacement of the \\
Apr 2013 & 0.8770 & 0.8914 & 0.9042 & 0.9152 & current month; \\
May 2013 & 0.8914 & 0.9042 & 0.9152 & 0.9256 & The displacement data is normalized into \\
Jun 2013 & 0.9042 & 0.9152 & 0.9256 & 0.9351 & the range of [0,1]; \\
\hline
\end{tabular}




\subsection{Prediction of periodic displacement}

\subsubsection{Causal factor analysis and input decision}

For the periodic displacement component, which shows small-scale fluctuations, external triggering factors are considered. As stated in Section 4.2, heavy precipitation and fluctuation of reservoir level are the main factors triggering the deformation of Baishuihe landslide from April to September.

The Baishuihe landslide is located in a rainy area where landslide deformation easily occurs. Rainfall infiltration may increase the sliding force which promotes landslide evolution: on the one hand, rainfall infiltration in landslides will increase the weight of the sliding mass; on the other hand, the accumulation of rainwater on thesliding surface will reduce the shear strength of sliding soil. Previous studies suggest the cumulated precipitation over the previous two months has a close relationship with landslide deformation (Keefer et al. 1987; Cao et al. 2013; Cao et al. 2016; Krkač et al. 2017; Bogaard and Greco 2018). In this study, the shapes of the precipitation of the one-month and two-months antecedent rainfall were coincident with the monthly displacement in general (Fig. 12). Therefore, the one-month and two-months antecedent rainfall were adopted as inputs to reflect the effect of precipitation (Table 3).

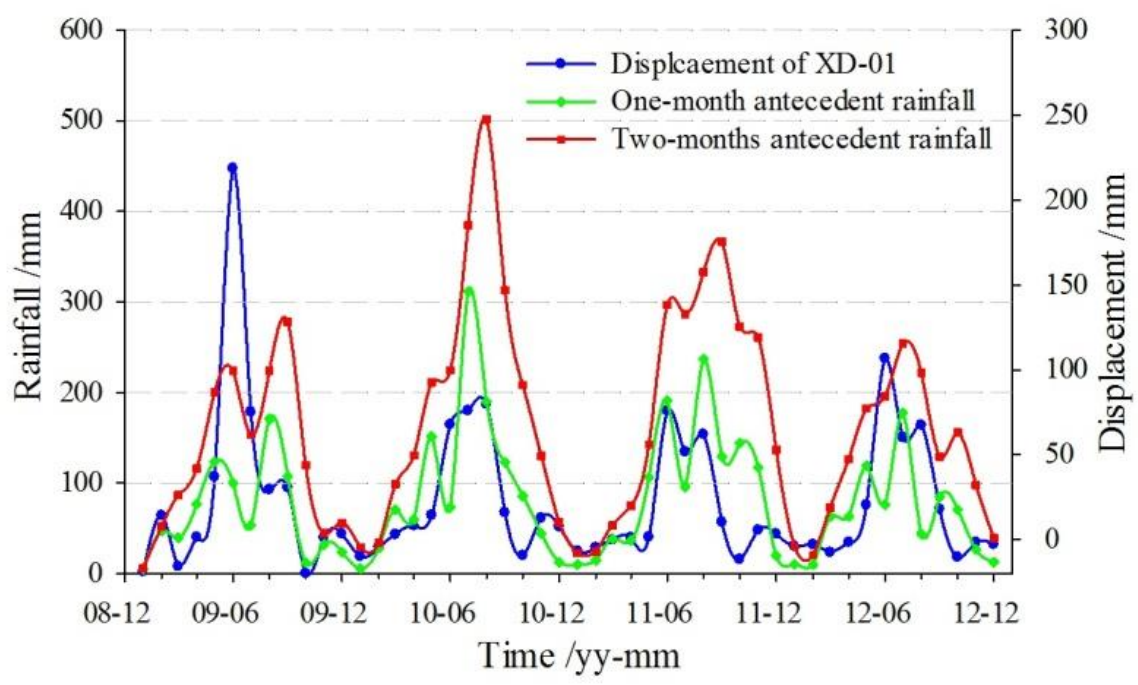

Fig. 12 The relationship between antecedent rainfall and the displacement of XD-01

The macroscopic deformation of the Baishuihe landslide occurred at the beginning of the TGRA impounding in 2003 (Table 1 and Fig. 8). The influence of the reservoir level fluctuation on landslide deformation mainly took place during the water level decline period (Fig. 13); the faster the reservoir level was descending, the greater the landslide deformed (Tang et al. 2015; Sun et al. 2017). For example, in May 2009, the landslide 
deformed 36mm when the reservoir level dropped 5.3m; under the similar precipitation condition in June 2009, the landslide displacement was $218 \mathrm{~mm}$ when the reservoir level dropped $8.7 \mathrm{~m}$ (Fig. 13). Moreover, landslide deformation varies with different elevations of reservoir level as well (Ren et al. 2015; Zhou et al. 2016). Hence, the variation rate and average elevation of reservoir level in the current month were applied as inputs to represent the effect of reservoir scheduling on landslide deformation (Table 3).

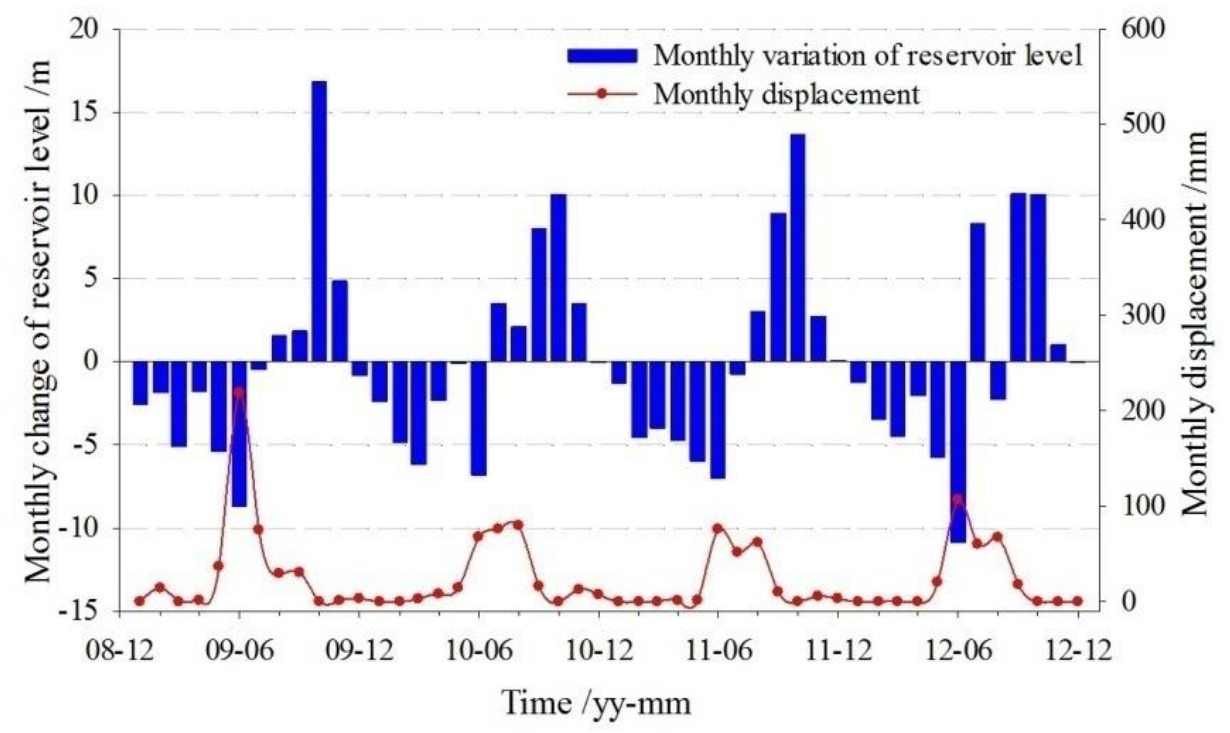

Fig. 13 Relationship between the displacement and reservoir water level variation

The current kinematic state of a landslide is another important factor for its dependence from external factors (Crozier 1986). Under varied evolution states, the response of landslide deformation to external triggering factors is totally different. For example, when the landslide is under stable conditions, even a strong precipitation may only cause slight deformation. In contrast, when the landslide is under an unstable evolution state, a slight precipitation may break the equilibrium of the original system and cause a sharp acceleration (Glade et al. 2005). Therefore, the displacement over the past 1, 2 and 3 months were adopted as inputs to represent the current evolution state (Zhou and Yin 2014) (Table 3).

Table 3. Inputs for periodic displacement modelling

\begin{tabular}{ll}
\hline Factors & Inputs 1-7 \\
\hline Precipitation & Input 1: the one-month antecedent rainfall \\
& Input 2: the two-months antecedent rainfall \\
Reservoir level & Input 3: the variation speed of reservoir level of the current month \\
& Input 4: the average elevation of reservoir level in the current month \\
Evolution state & Input 5: the displacement over the past 1 month \\
& $\begin{array}{l}\text { Input 6: the displacement over the past } 2 \text { month } \\
\text { Input 7: the displacement over the past 3 month }\end{array}$ \\
\hline
\end{tabular}




\begin{tabular}{llllllllll}
\hline Time & Input 1 & Input 2 & Input 3 & Input 4 & Input 5 & Input 6 & Input 7 & Output & Notes \\
\hline Jan 2013 & 0.0274 & 0.9248 & 0.2519 & 0.0251 & 0.5960 & 0.5450 & 0.4890 & 0.4480 & The detail information of inputs is \\
Feb 2013 & 0.0411 & 0.7715 & 0.1822 & 0.0274 & 0.5450 & 0.4890 & 0.4480 & 0.4240 & shown in Table 3; \\
Mar 2013 & 0.1578 & 0.6259 & 0.2370 & 0.0411 & 0.4890 & 0.4480 & 0.4240 & 0.3830 & Output is the periodic displacement \\
Apr 2013 & 0.1898 & 0.5674 & 0.3019 & 0.1578 & 0.4480 & 0.4240 & 0.3830 & 0.3640 & of the current month; \\
May 2013 & 0.3729 & 0.4058 & 0.0548 & 0.1898 & 0.4240 & 0.3830 & 0.3640 & 0.4080 & The data was normalized into the \\
Jun 2013 & 0.5683 & 0.0556 & 0.1745 & 0.3729 & 0.3830 & 0.3640 & 0.4080 & 0.7520 & range of [0,1]. \\
\hline
\end{tabular}

\subsubsection{Modelling and prediction of periodic displacement}

Based on the deformation analysis of Baishuihe landslide, seven causal factors were taken as inputs, and the periodic displacement was considered as the output. As with the modelling of trend displacement, the monthly displacement from January 2009 to December 2012 was used to train, and the monthly displacement from January to December in 2013 was used for testing. Some samples of the data used in the modelling of periodic displacement are shown in Table 4. The forecasting model of periodic displacement was established with the application of PSO and KELM. Furthermore, in order to compare the prediction performance of multi-factor PSO-KELM, four other methods were adopted to predict the periodic displacement, namely the single-factor PSO-KELM, multi-factor ELM, multi-factor SVR, and multi-factor BPNN. The parameters and inputs of these methods are shown in Table 5.

Table 4 Some data samples used in the modelling of periodic displacement

\begin{tabular}{|c|c|c|c|}
\hline Model & Description & Parameter & Notes \\
\hline Multi-factor & PSO-KELM model with consideration of causal factors. & $c=985.4135$ & $c$ is the regularization coeffcient; $\gamma$ is \\
\hline PSO-KELM & Inputs: input $1 \sim 7$ & $\gamma=0.6240$ & the parameter of Kernel function. \\
\hline Single-factor & PSO-KELM model without consideration of triggering factors. & $c=133.5672$ & \\
\hline PSO-KELM & Inputs: input $5 \sim 7$ & $\gamma=49.8052$ & \\
\hline $\begin{array}{l}\text { Multi-factor } \\
\text { ELM }\end{array}$ & $\begin{array}{l}\text { ELM model with consideration of causal factors. } \\
\text { Inputs: input } 1 \sim 7 \text {. }\end{array}$ & $n=15$ & $\begin{array}{l}n \text { is the number of neurons in hidden } \\
\text { layer. }\end{array}$ \\
\hline $\begin{array}{l}\text { Multi-factor } \\
\text { SVM }\end{array}$ & $\begin{array}{l}\text { SVM model with consideration of causal factors. } \\
\text { Inputs: input } 1 \sim 7 \text {. }\end{array}$ & $\begin{array}{l}p=115.0016 \\
g=0.0281\end{array}$ & $\begin{array}{l}p \text { is the penalty factor; } g \text { is the } \\
\text { parameter of kernel function. }\end{array}$ \\
\hline $\begin{array}{l}\text { Multi-factor } \\
\text { BPNN }\end{array}$ & $\begin{array}{l}\text { BPNN model with consideration of causal factors. } \\
\text { Inputs: input } 1 \sim 7 \text {. }\end{array}$ & $\begin{array}{l}m=20 \\
a=0.9 \\
r=0.05\end{array}$ & $\begin{array}{l}m \text { is the number of neurons in hidden } \\
\text { layer; } a \text { is the momentum; } r \text { is the } \\
\text { learning rate. }\end{array}$ \\
\hline
\end{tabular}

300

As shown in Fig. 14 and Table 6, the predicted values of the five models show high agreement with the measured values. However, the single-factor PSO-KELM, multi-factor ELM, SVR, and BPNN did not perform well during the step-like deformation period. The performance criteria indicates that the multi-factor PSO-KELM achieved the best performance with RMSE, MAPE and R values of 18.104, 0.083 and 0.983, respectively. 

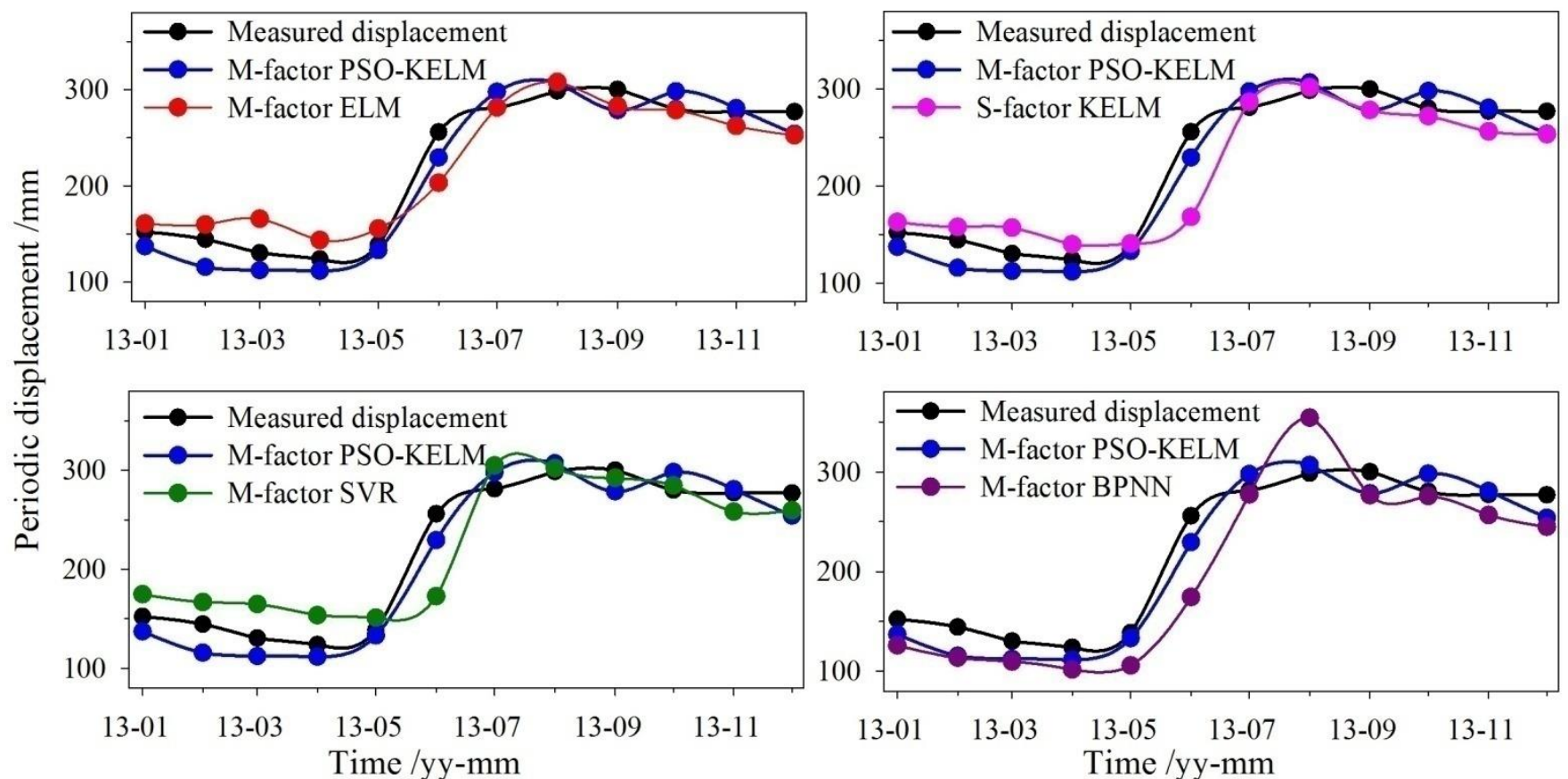

Fig. 14 The predicted and measured values of periodic displacement (M-factor means multi-factor, and S-factor means single-factor)

\begin{tabular}{llll}
\multicolumn{4}{c}{ Table 6 The prediction accuracy of periodic displacement } \\
\hline Models & RMSE & MAPE & R \\
\hline Multi-factor PSO-KELM & 18.104 & 0.083 & 0.983 \\
Single-factor PSO-KELM & 29.572 & 0.095 & 0.918 \\
Multi-factor ELM & 22.761 & 0.096 & 0.958 \\
Multi-factor SVR & 32.087 & 0.125 & 0.906 \\
Multi-factor BPNN & 34.515 & 0.147 & 0.943 \\
\hline
\end{tabular}

\subsection{Prediction of total displacement}

The predicted total displacement was obtained by adding the predicted trend and periodic displacements together. As stated in Section 4.4, the time series of trend displacement is smooth and can be easily predicted, so it was predicted applying the same model of PSO-KELM. As shown in Fig. 15, the predicted total displacement of multi-factor PSO-KELM shows the best agreement with the measured total displacement, while the RMSE, MAPE and $\mathrm{R}$ are $18.418,0.494 \%$ and 0.991 , respectively (Table 7). Furthermore, during the step-like deformation, multi-factor PSO-KELM shows excellent prediction performance as well. For example, jointly affected by heavy precipitation and decreasing of reservoir level, Baishuihe landslide deformed sharply in June 2013, and the multi-factor PSO-KELM achieved precise prediction by establishing the accurate response relationship between triggering factors and deformation, the APE of the predicted value is only $0.670 \%$ (Fig. 16). The four compared methods also performed well most of the time, but all of them achieved less accurate prediction in the crucial 

multi-factor ELM, SVR, BPNN are 2.511\%, 1.463\%, 2.448\% and 2.323\%, respectively (Fig. 16).
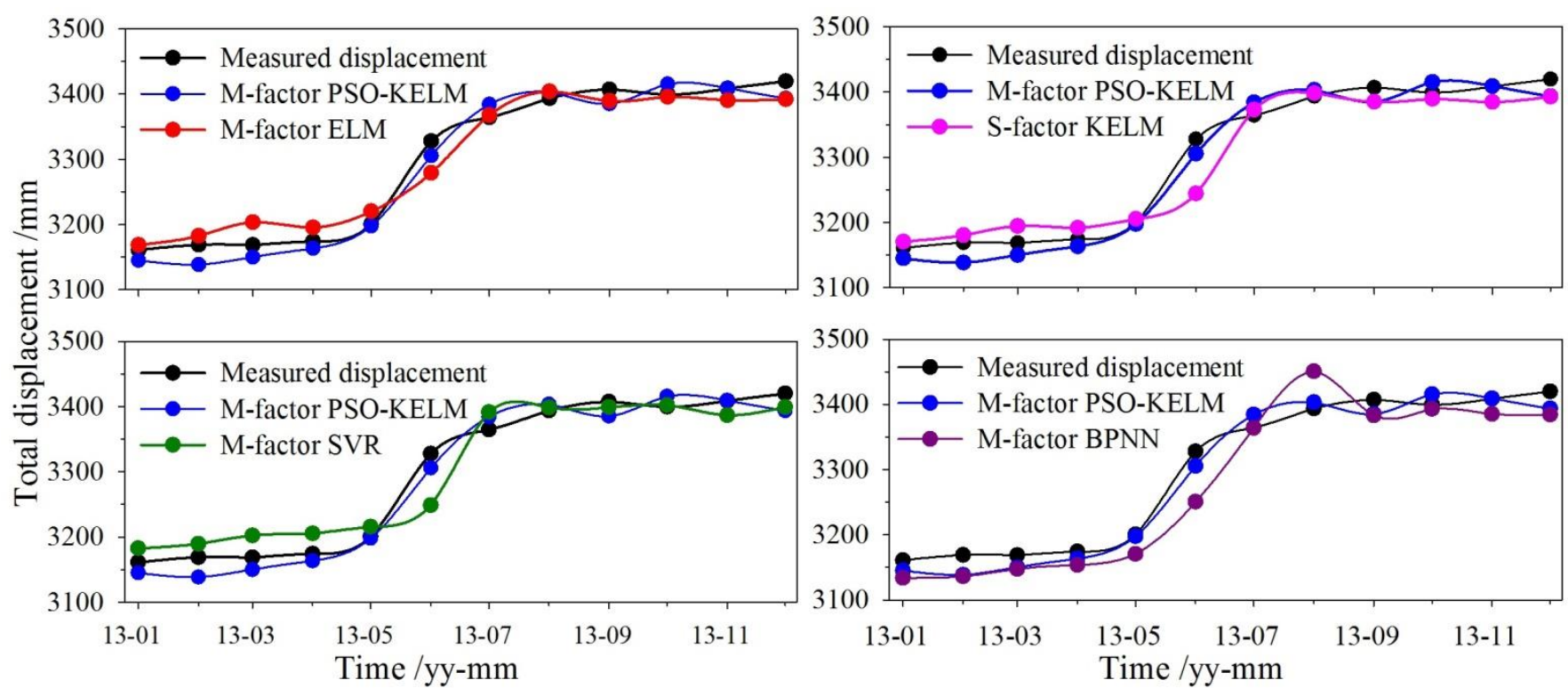

Fig. 15 The predicted and measured values of total displacement (M-factor means multi-factor, and $\mathrm{S}$-factor means single-factor)

Table 7 The prediction accuracy of total displacement

\begin{tabular}{llll}
\hline Models & RMSE & MAPE & R \\
\hline Multi-factor PSO-KELM & 18.418 & $0.494 \%$ & 0.991 \\
Single-factor PSO-KELM & 29.125 & $0.626 \%$ & 0.969 \\
Multi-factor ELM & 22.709 & $0.574 \%$ & 0.984 \\
Multi-factor SVR & 31.910 & $0.777 \%$ & 0.965 \\
Multi-factor BPNN & 35.628 & $0.899 \%$ & 0.971 \\
\hline
\end{tabular}

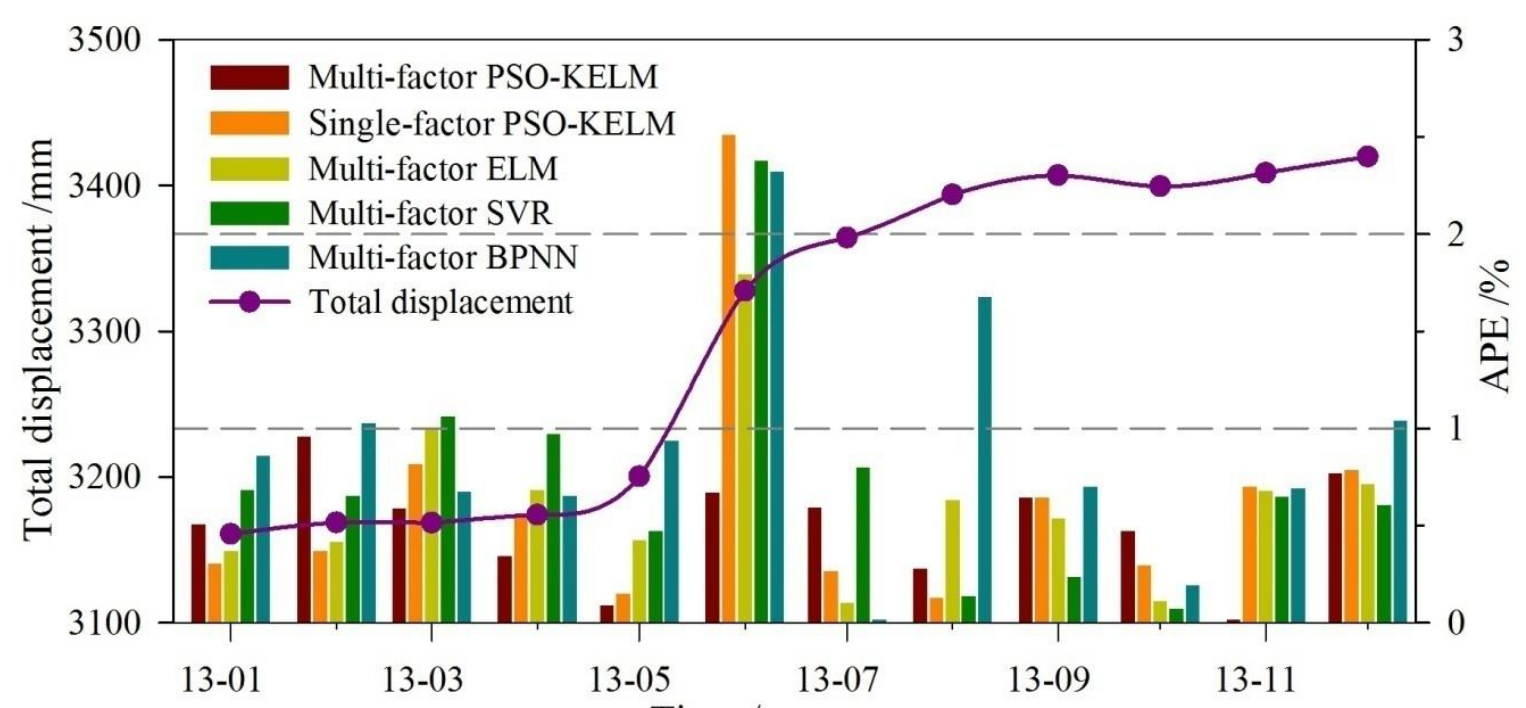

Time /yy-mm

Fig. 16 The error comparison of the five methods 


\section{Discussion}

\subsection{Early warning application}

Landslide prediction is an important component of early warning system which is essential for landslide prevention and mitigation (Sassa et al. 2009; Intrieri et al., 2013; Mazzanti et al., 2015; Intrieriand Gigli 2016). ML methods and in general all data-based predictive models (such as those cited in the introduction section) use past monitoring data as the foundation for their forecast. To monitor a phenomenon's parameter, a longer time series (preferably at least 1 year) allows to better express its whole variability and complete range of behaviors, such as seasonal oscillations, level of noise and trend. A slope collapse is usually an unprecedented event characterized by peaks in deformation rate and acceleration. It typically represented by the maximum values in the time series. If ML methods do not have a precedent history of such events to train with, it is not possible to forecast them and therefore to provide a time of failure. Furthermore, the output of such models is not a time (of failure) but a displacement value, underlying that their purpose is not directly to provide an estimation of the moment of collapse of a landslide.

Nonetheless, the predictive capacities of models such as the PSO-KELM can still be useful in an early warning perspective. In fact, predicted displacements can be used to set warning thresholds (Crosta and Agliardi 2012) and to recognize when the landslide undergoes an unpredicted acceleration that can therefore be considered anomalous and trigger the necessary early warning procedures. For example, such models can detect anomalous displacements relatable with the initiation of the tertiary creep stage (Fig. 1a). At that point, time of failure forecasting methods (Saito, 1969; Fukuzono, 1985; Mufundirwa et al., 2010) could be run in parallel until either the collapse occurs or the landslide reaches a new equilibrium. The same application was envisaged by Carlà et al. (2016) and Miao et al. (2018) using similar approaches. Such method permits to overcome the setting of thresholds based only on expert judgement but has a major drawback of requiring a long time series of monitoring data.

\subsection{Performance of PSO-KELM and future developments}

By comparing the multi-factor ELM, SVR and BPNN, it is found that the prediction capacity of ELM is better than SVR and BPNN, that is agreed with the previous scientific literature (Lian et al. 2014; Cao et al. 2016; Huang et al. 2017). However, in the application on landslide displacement prediction, one drawback of the ELM is that the prediction results vary with its random connection weight between the input and the hidden layer. As shown in Fig. 
17, although the inputs and parameter of the ELM are the same, 4 sets of predicted periodic displacements are different, especially in the step-like deformation period. ELM can achieve accurate predictions, but inaccurate predictions occur sometimes, with the risk of misleading the decisions of disaster managers. In order to avoid the random factor within the prediction process, kernel learning was introduced into ELM, and the KELM was proposed. In this study, the hybrid model of PSO-KELM was applied in landslide displacement prediction. Moreover, compared the prediction results of the multi-factor PSO-KELM and ELM (Fig. 15 and 16), we can find that the PSO-KELM has a stronger prediciton capacity.

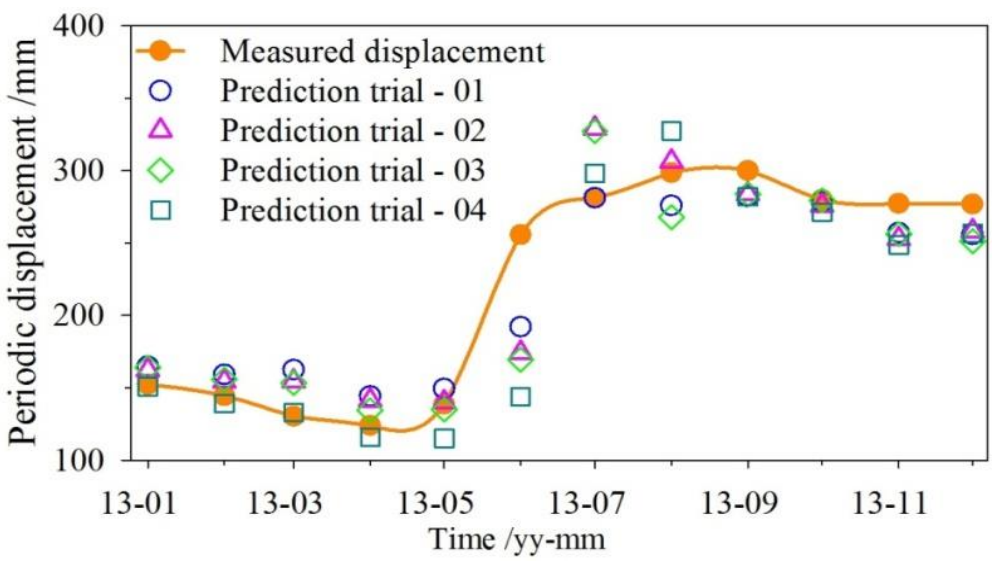

Fig. 17 The prediction accuracy comparisons between different trials of ELM

As shown in Fig. 15 and 16, compared with the multi-factor PSO-KELM, the single-factor PSO-KELM performed worse in the step-like deformation period. The sharp increase of the displacement plays a significant role in the evolution process of the step-like landslide, the speed and increase of which are controlled by the triggers (the precipitation and the reservoir fluctuation). The single-factor PSO-KELM method cannot simulate the relationship between the deformation and the triggers, that is the reason why the large difference exists. Hence, in order to achieve accurate prediction in the step-like deformation period, the triggering factors should be considered.

Landslide displacement prediction can be implemented accurately by integrating the application of ML technique and engineering geology. However, the cost of some professional monitoring devices, such as GPS, clinometers et al. may limit the application of the proposed model. The development of satellite radar interferometry provides effective methods to solve this tough problem. In future studies, open-access satellite data (such as Sentinel-1) and advanced InSAR time series processing techniques will be applied to extract landslide deformation information, which can be used as basic data to achieve economic and effective landslide prediction. 


\section{Conclusions}

The Baishuihe landslide in the TGRA has a typical step-like deformation behavior. It experiences sudden accelerations from April to September under the combined influence of precipitation and reservoir water level variation, while it is almost stable during the rest of the year. The landslide is under a steady deformation state in large time scale and deforms retrogressively with the stronger deformation in the eastern and front part.

The sequence of the total cumulated displacement can be decomposed into trend displacement and periodic displacement by wavelet transform, while the noise component was eliminated. The trend displacement shows approximately monotonically increasing controlled by geological conditions, while the periodic displacement shows periodic fluctuations induced by triggering factors. The two displacement items were predicted by the PSO-KELM model with different inputs separately; and the predicted total displacement was obtained from the summation. The REMS, MAPE and R of the predicted result are calculated as $18.418,0.494 \%$ and 0.991 , respectively. It indicates that the proposed method can achieve excellent performance in displacement prediction.

The accurate prediction of periodic displacement is the key to landslide displacement prediction. In this process, the causal factors (rainfall, reservoir level and landslide evolution state) enable to simulate the response relationship between the triggering factors and landslide deformation. The prediction accuracy can be improved by considering the causal factors, especially in case of step-like deformation.

The PSO-KELM integrated both the advantages of PSO and KELM algorithm, where KELM has high prediction performance, and PSO can seek appropriate parameters of KELM. The multi-factor PSO-KELM can simulate the response relationship between triggering factors and landslide deformation better than the methods of multi-factor ELM, SVR and BPNN. In addition, the prediction of the PSO-KELM is found stable, that is crucial for developing a landslide early warning system.

Overall, the proposed method, which applies the ML techniques and landslide evolution theory, can achieve accurate and stable prediction in case of the slow and step-like deformation period. This novel method can be recommended to conduct landslide displacement prediction in the TGRA and other landslide-prone regions. 


\section{Acknowledgements}

This paper was prepared as part of the projects "The study of mechanism and forecast criterion of the gentle-dip landslides in The Three Gorges Reservoir Region, China" (No. 41572292) and "Study on the hydraulic properties and the rainfall infiltration law of the ground surface deformation fissure of colluvial landslides" (No. 41702330) funded by the National Natural Science Foundation of China. The comments from the anonymous reviewers and the editors have significantly improved the quality of this article. The first author would like to thank the China Scholarship Council for funding his research at the University of Florence, Italy.

\section{References}

An, H., Viet TT, Lee G, Kim Y, Kim M, Noh S, Noh J (2016) Development of time-variant landslide-prediction software considering three-dimensional subsurface unsaturated flow. Environ Modell Softw 85: 172-183

Barzegar R, Adamowski J, Moghaddam AA (2016) Application of wavelet-artificial intelligence hybrid models for water quality prediction: a case study in Aji-Chay River, Iran. Stoch Env Res Risk A 30(7): 1797-1819

Bogaard T, Greco R (2018) Invited perspectives: Hydrological perspectives on precipitation intensity-duration thresholds for landslide initiation: proposing hydro-meteorological thresholds. Nat Hazard Earth Sys 18(1): 31-39

Cao Y, Yin K, Alexander DE, Zhou C (2016) Using an extreme learning machine to predict the displacement of step-like landslides in relation to controlling factors. Landslides 13(4): 725-736

Cao Y, Yin K, Zhou C (2013) Comprehensive assessment on Sanzhouxi landslide stability considering displacement monitoring. Electr J Geol Eng 18: 5507-5524

Carlà T, Intrieri E, Di Traglia F, Casagli N (2016) A statistical-based approach for establishing probabilistic warning thresholds of flank eruption occurrence using one-step ahead forecasts of displacement time series. Nat Hazards 84(1): 669-683

Carlà T, Intrieri E, Farina P, Casagli N (2017) A new method to identify impending failure in rock slopes. Int J 
Casagli N, Catani F, Del Ventisette C, Luzi G (2010) Monitoring, prediction, and early warning using ground-based radar interferometry. Landslides 7(3): 291-301

Chen Q, Kou X, Huang S, Zhou Y (2004) The distributes and geologic environment characteristics of red beds in China. J Eng Geol 12 (1): 34-40 landslides. Landslides 14(1): 35-45

Corominas J, Moya J, Ledesma A, Lloret A, Gili JA (2005) Prediction of ground displacements and velocities from groundwater level changes at the Vallcebre landslide (Eastern Pyrenees, Spain). Landslides 2(2): 83-96

Crosta GB, Agliardi F (2012) How to obtain alert velocity thresholds for large rockslides. Physics and Chemistry of the Earth 27(36):41 1557-1565

Crozier MJ (1986) Landslides: causes, consequences \& environment. Taylor \& Francis

Daubechies I (1990) The wavelet transform, time-frequency localization and signal analysis. IEEE T Inform Theory 36(5): 961-1005

Daubechies I (1992) Ten lectures on wavelets. Society for industrial and applied mathematics

Du J, Yin K, Lacasse S (2013) Displacement prediction in colluvial landslides, Three Gorges Reservoir, China. Landslides 10(2): 203-218

Eberhart R, Kennedy J (1995) A new optimizer using particle swarm theory. In: Micro Machine and Human Science, 1995. MHS'95., Proceedings of the Sixth International Symposium on, pp. 39-43

Eid HT (2014) Stability charts for uniform slopes in soils with nonlinear failure envelopes. Eng Geol 168: 38-45

Fukuzono T (1985) A new method for predicting the failure time of a slope. Proceedings of the 4th International Conference and Field Workshop in Landslides Tokyo 
Glade T, Anderson M, Crozier MJ (2005) Landslide hazard and risk: issues, concepts and approach. Landslide Hazard and Risk Wiley pp: 1-40

Haar A (1910) Zur theorie der orthogonalen funktionensysteme. Math Ann 69(3): 331-371

Huang F, Huang J, Jiang S, Zhou C (2017) Landslide displacement prediction based on multivariate chaotic model and extreme learning machine. Eng Geol 218: 173-186

Huang G, Zhou H, Ding X, Zhang R (2012) Extreme learning machine for regression and multiclass classification. IEEE Transactions on Systems Man and Cybernetics Part B (Cybernetics) 42(2): 513-529

Huang G, Zhu Q, Siew C (2004) Extreme learning machine: a new learning scheme of feedforward neural networks. In: Neural Networks 2004 Proceedings pp: 985-990

Huang G, Zhu Q, Siew C (2006) Extreme learning machine: theory and applications. Neurocomputing 70(1): 489-501

Intrieri E, Gigli G (2016) Landslide forecasting and factors influencing predictability. Natural Hazards and Earth System Sciences, 16(12): 2501-2510

Intrieri E, Gigli G, Casagli N, Nadim F (2013) Brief communication: Landslide Early Warning System: Toolbox and General Concepts. Natural Hazards and Earth System Sciences, 13: 85-90

Keefer DK, Wilson RC, Mark RK, Brabb EE, Brown III WM, Ellen SD, Harp EL, Wieczorek GF, Alger CS, Zatkin RS (1987) Real-time landslide warning during heavy rainfall. Science 238(4829): 921-926

Krkač M, Špoljarić D, Bernat S, Arbanas SM (2017) Method for prediction of landslide movements based on random forests. Landslides 14(3): 947-960

Li D, Yin K, Leo C (2010) Analysis of Baishuihe landslide influenced by the effects of reservoir water and rainfall. Environ Earth Sci 60(4): 677-687.

Lian C, Zeng Z, Yao W, Tang H (2014) Extreme learning machine for the displacement prediction of landslide 
under rainfall and reservoir level. Stoch Env Res Risk A 28: 1957-1972

Lima AR, Cannon AJ, Hsieh WW (2015) Nonlinear regression in environmental sciences using extreme learning machines: a comparative evaluation. Environ Modell Softw 73: 175-188

Liu Y, Liu D, Qin Z, Liu F, Liu L (2016) Rainfall data feature extraction and its verification in displacement prediction of Baishuihe landslide in China. B Eng Geol Environ 75(3): 897-907

Ma J, Tang H, Liu X, Hu X, Sun M, Song Y (2017) Establishment of a deformation forecasting model for a step-like landslide based on decision tree C5.0 and two-step cluster algorithms: a case study in the Three Gorges Reservoir area, China. Landslides 14(3): 1275-12281

Mallat SG (1989) A theory for multi-resolution signal decomposition: the wavelet representation. IEEE T Pattern Anal 11(7): 674-693

Mazzanti P, Bozzano F, Cipriani I, Prestininzi A (2015) New insights into the temporal prediction of landslides by a terrestrial SAR interferometry monitoring case study. Landslides, 12(1): 55-68

Meyer Y (1990) Ondelettes et opérateurs. Paris Hermann

Miao H, Wang G, Yin K, Kamai T, Li Y (2014) Mechanism of the slow-moving landslides in Jurassic red-strata in the Three Gorges Reservoir, China. Eng Geol 171: 59-69

Miao F, Wu Y, Xie Y, Li Y (2018) Prediction of landslide displacement with step-like behavior based on multialgorithm optimization and a support vector regression model. Landslides 15(3): 475-488

Mufundirwa A, Fujii Y, Kodama J (2010) A new practical method for prediction of geomechanical failure-time. Int J Rock Mech Min 47(7):1079-1090

Petley D (2012) Global patterns of loss of life from landslides. Geology 40(10): 927-930

Ren F, Wu X, Zhang K, Niu R (2015) Application of wavelet analysis and a particle swarm-optimized support vector machine to predict the displacement of the Shuping landslide in the Three Gorges, China. Environ 
Saito M (1965) Forecasting the time of occurrence of a slope failure. In: Proceedings of the 6th international conference on soil mechanics and foundation engineering pp: 537-541

Saito M (1969) Forecasting time of slope failure by tertiary creep. In: Proceedings of 7th international conference on soil mechanics and foundation engineering pp: 677-683

Sassa K, Picarelli L, Yin Y (2009) Monitoring, prediction and early warning. In: Landslides-Disaster Risk Reduction Springer Berlin Heidelberg pp: 351-375

Sun G, Yang Y, Jiang W, Zheng H (2017) Effects of an increase in reservoir drawdown rate on bank slope stability: A case study at the Three Gorges Reservoir, China. Eng Geol 221: 61-69

Tang H, Li C, Hu X, Wang L, Criss R, Su A, Wu Y, Xiong C (2015) Deformation response of the Huangtupo landslide to rainfall and the changing levels of the Three Gorges Reservoir. B Eng Geol Environ 74(3): 933-942

Vasu NN, Lee S (2016) A hybrid feature selection algorithm integrating an extreme learning machine for landslide susceptibility modeling of Mt. Woomyeon, South Korea. Geomorphology 263: 50-70

Wu X, Benjamin Zhan F, Zhang K, Deng Q (2016) Application of a two-step cluster analysis and the Apriori algorithm to classify the deformation states of two typical colluvial landslides in the Three Gorges, China. Environ Earth Sci 75(2): 146-161

Yabe H, Hayasaka I (1920) Geographical Research in China, 1911-1916: Reports. Paleontology of Southern China. Tokyo Geographical Society, Tokyo

Yang Z, Ce L, Lian L (2017) Electricity price forecasting by a hybrid model, combining wavelet transform, ARMA and kernel-based extreme learning machine methods. Appl Energ 190: 291-305

Zhou C, Yin K (2014) Landslide displacement prediction of WA-SVM coupling model based on chaotic sequence. 
Zhou C, Yin K, Cao Y, Ahmed B (2016) Application of time series analysis and PSO-SVM model in predicting the Bazimen landslide in the Three Gorges Reservoir, China. Eng Geol 204: 108-120 applying machine learning methods: A case study from Longju in the Three Gorges Reservoir area, China. Comput Geosci 112: 23-27

Zhu X, Xu Q, Tang M, Nie W, Ma S, Xu Z (2017) Comparison of two optimized machine learning models for predicting displacement of rainfall-induced landslide: A case study in Sichuan Province, China. Eng Geol 218: 